\title{
إطار استراتيجى للتنمية الزراعية والأمن الغذائى فى مصر للسنوات
}

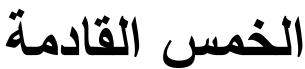

أ.د. سعد نصار"

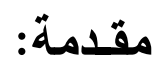

يعتبر قطاع الزراعة فى مصر ركيزة من الركائز الأساسية فى الاقتصاد القومى حيث

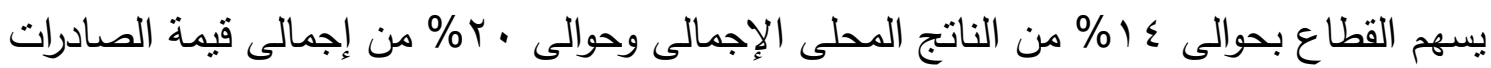
السلعية وحوالى • ب\% من إجمالى القوة العاملة فى الاقتصاد القومى علاوة على توفير الغذاء للسكان والمواد الخام اللازمة للصناعة الوطنية. كما أن الزراعة تعتبر سوقا للعديد من المنتجات الصناعية كالآلات والمعدات الزراعية والاسمدة الكيميائية ومبيدات الآفات الزراعية والامصال واللقاحات البيطرية. هذا علاوة على مساهمة الزراعة فى عملية التراكم الرأسمالى فى الاقتصاد

وتستهدف استراتيجية التتمية الزراعية فى مصر مايلى: تحقيق معدل نمو زراعى يصل إلى حوالى 0, §\% \% 0 \% سنوياً.

تحسين نسب الاكثفاء الذاتى من المحاصيل الغذائية الاستراتيجية والتى تعانى فيها مصر من فجوة غذائية أو عجز • ومن الجدير بالذكر أن مصر لديها أكتقاء ذاتى من مجموعة من المحاصيل الغذائية كالخضر والفاكهة ولديها شبه اكتفاء ذاتى من الدواجن والبيض والألبان الطازجة والأسماك. فى حين تعانى مصر من فجوة غذائية أو عجز فى مجموعات غذائية أخرى وهى:

" استاذ الاقتصاد الزراعى بجامعة القاهرة - عميد كلية الزراعة بالفيوم ورئيس مركز البحوث الزراعية ومحافظ الفيوم

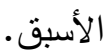


- القمح والذى تصل نسبة الاكتفاء الذاتى منه حاليا إلى حوالى ه4\% فقط (حيث يبلغ الإنتاج منه

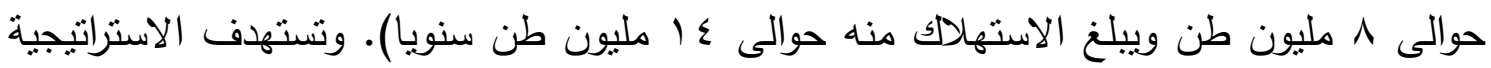
زيادة نسبة الاكثفاء الذاتى من القمح إلى ٪0\% خلال السنوات الخمس القادمة.

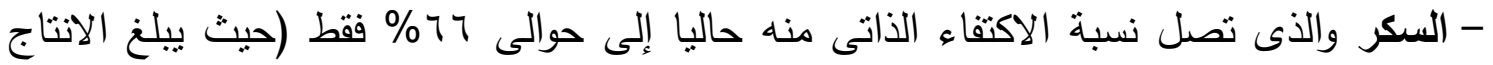
منه حوالى Y, r, مليون طن نصفه من محصول قصب السكر والنصف الثانى من محصول البنجر وييلغ الاستهلاك منه حوالى r,r مليون طن سنويا). وتستهدف الاستراتيجية تحقيق الاكتفاء الذاتى

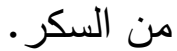

- الزيوت النباتية والتى تصل نسبة الاكتفاء الذاتى منها حاليا إلى حوالى ب ا \% فقط سنويا (حيث

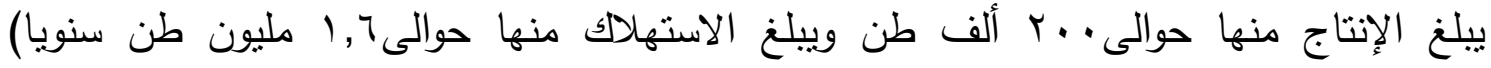

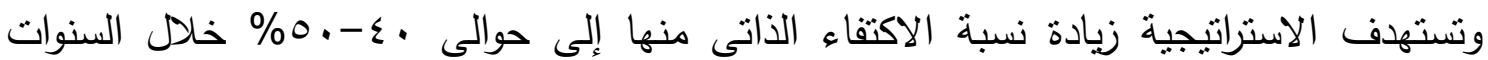

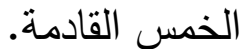

- الفول البلاى والذى تصل نسبة الاكتفاء الذاتى منه حاليا إلى حوالى بr\% فقط (حيث يبلغ

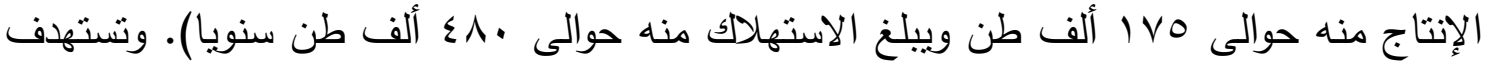

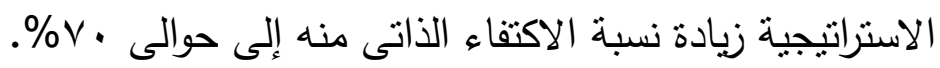
- البروتين الحيوانى والذى يصل متوسط نصيب الفرد منه من مصادره المختلفة (اللحوم الحمراء

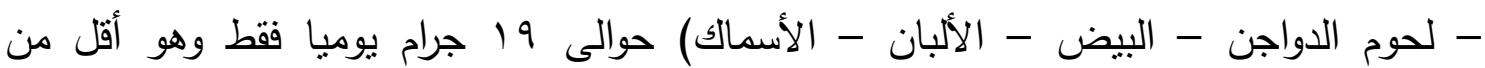
المتوسطات العالمية والتى تصل إلى حوالى 9 جرام يوميا. وتستهدف الاستراتيجية زيادة نصيب

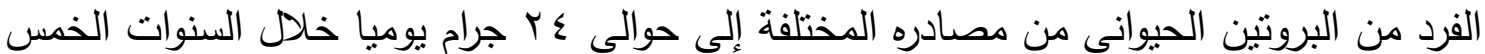


تحقيق درجة أعلى من الأمن الغذائى بمفهومه الواسع والاستفادة من المزايا النسبية والتتافسية

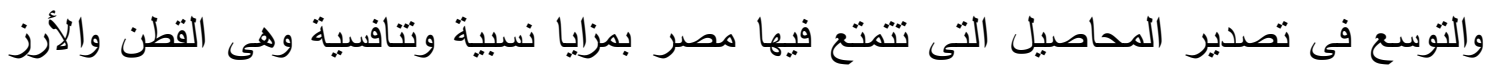
والخضر والفاكهة والنباتات الطبية والعطرية وزهور القطف. توفير المواد الخام الزراعية اللازمة للصناعة الوطنية وخاصة صناعة الغزل والنسيج والصناعات الغذائية. توفير فرص عمل منتجة فى قطاع الزراعة والأنشطة الريفية المرتبطة به.

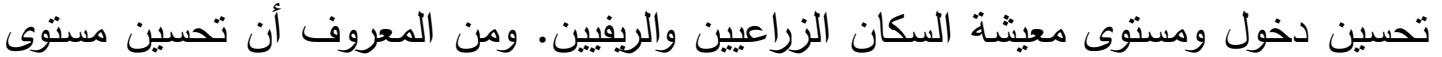
المعيثة يتضمن بالإضافة إلى تحسين الدخول تحسين مسنوى الخدمات التى تقدم للسكان الزراعيين والريفيين منل خدمات التعليم والتأمين الصحى والمعانشات ومياه الثرب والصرف الصحى والكهرباء والطرق وسبل الاتصال.

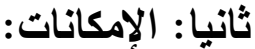

هذا ويمنلك قطاع الزراعة فى مصر العديد من الإمكانات والمقومات الأرضية والمائية

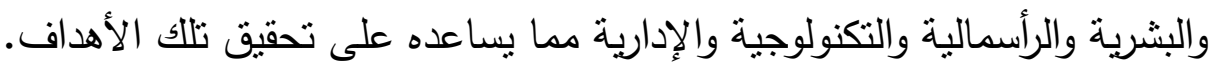

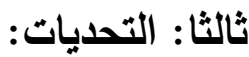

إلا أن القطاع يواجه فى نفس الوقت - كغيره من قطاعات الزراعة فى الدول العربية والنامية - العديد من التحديات المحلية والاقليمية والدولية مثل التغيرات المناخية العالمية وندرة المياه والتصحر واتساع المناطق الجافة والأراضى القاحلة والحفاظ على البيئة والتتوع البيولوجى وضعف الاستثمارات والانتاجية الزراعية وارتقاع معدل زيادة السكان والفجوة الغذائية وأزمة الغذاء العالمية والأزمة المالية والاقتصادية العالمية والأمراض النباتية والحيوانية العابرة واستخدام الغذاء

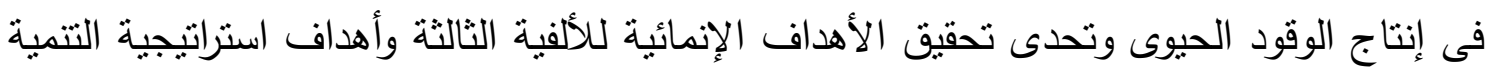
المستدامة · • •r وخاصة محاربة الفقر والجوع. 
ولتحقيق تلك الأهداف والاستفادة القصوى من الإمكانات والمقومات المتاحة ومواجهة التحديات القائمة فإنه لابد من تبنى العديد من الآليات أى السياسات والخطط والبرامج والمشروعات الخاصة بالتوسع الأفقى (استصلاح واستزراع أراضى جديدة) والتوسع الرأسى (زيادة إنتاجية الوحدة من الأرض والمياه والعمل ورأس المال). ويمكن ذكر أهم تللك الآليات أى السياسات والخطط والبرامج والمشروعات فيما يلى: التوسع الافقىى: - م

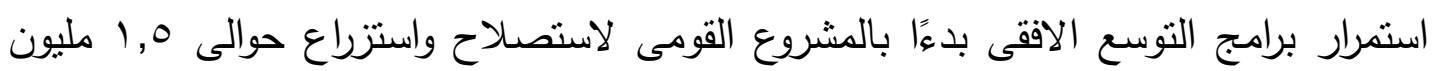
فدان جديدة والذى بشمل حوالى V Vوقعاً فى ^ محافظات (الجيزة - المنيا - قنا - أسوان الوادى الجديد - سيناء - الاسماعيلية - مطروح) ويقع حوالى 70\% من مساحته فى صعيد مصر وبما يعكس الاهتمام بالأقاليم الأكثز احتياجاً والتى لم تنل حظها الملائم من مشروعات التتمية.

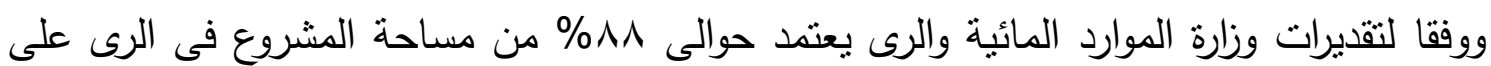
المياه الجوفية فى حين يعتمد حوالى ب / \% من مساحة المشروع فى الرى على مياه النيل وأن هذه المياه تكفى للرى لمدة . . 1 على الأقل. هذا وتعد الحكومة من خلال شركة الريف المصرى الجديد والهيئة العامة لمشروعات التعمير والتنمية الزراعية وبنظام الثباك الواحد خربطة استثمارية بمساحات وأماكن الاراضى القابلة للاستصلاح والاستزراع والاستثار من قبل المنتفعين (شباب الخريجين - صغار مزارعين - صغار مستثرين - كبار مستثمرين) ومصادر مباه الرى وأسلوب التصرف سواءًا بالبيع أو بحق الانتفاع والحدود القصوى للملكية وطرق التسعير سواءاً بالمزاد أو الاسعار التى تحددها اللجنة العليا لتثمين أراضى الدولة ومسئولية الحكومة والمنتقعين فى إقامة مشروعات البنية القومية والاساسية لتلك الأراضى. هذا وقد طرحت شركة الريف المصرى الجديد كراسات الشروط للمرحلة الأولى من المشروع ( ..0 ألف فدان) وهى فى طريقها للبت فى 


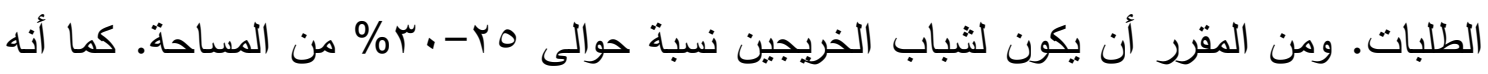

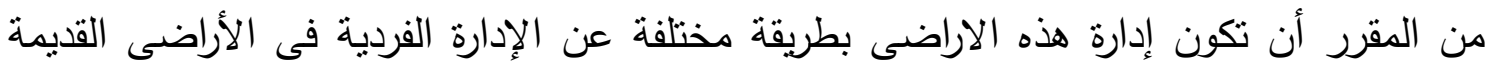

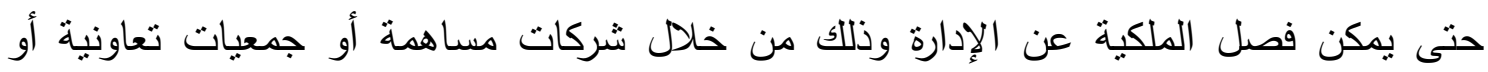
شركات إدارة أعمال زراعية لتجنب مشاكل تفتيت الحيازات والاستفادة من وفورات السعة واستخدام التكنولوجيات الحديثة فى الزراعة كالرى المطور والصوب الزراعية واستخدام الطاقة الثمسية

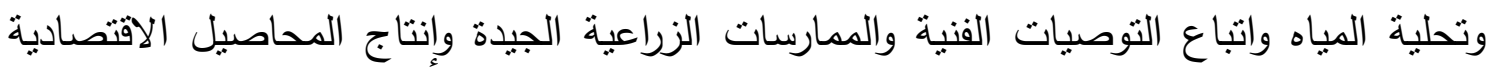
للاستهلاك المحلى والتصدير وذات الاحتباجات المائية الأقل. هذا وقد أعد مركز البحوث الزراعية

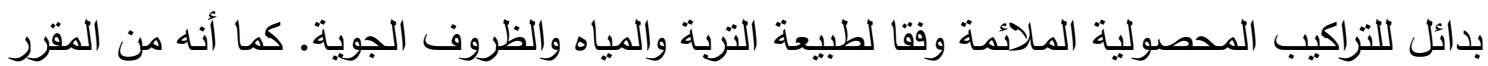
التوسع فى التصنيع الزراعى والغذائى وإقامة المجمعات الزراعية الصناعية بموقع المشروع بما يزيد من القيمة المضافة ويفتح فرص عمل منتجة جديدة. ويرتبط بذلك كله إقامة مجتمعات عمرانية جديدة متكاملة الجوانب من حيث الإنتاج والخدمات. فليس من المعقول أن نظل المساحة المأهولة

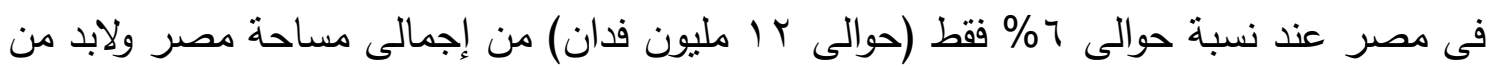
زيادة هذه النسبة لتصل إلى حوالى 0ro\% (حوالى آ مليون فدان) وذلك لتخفيف التكس السكانى فى الوادى والدلتا.

ترشيد استخدام مياه الرى فى الزراعة:

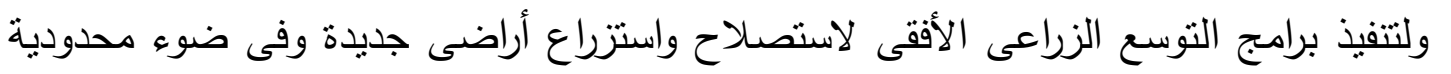

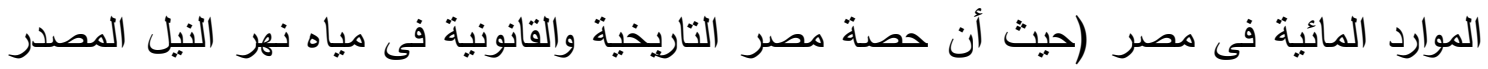
الرئيسى للمياه فى مصر والتى تحرص وتؤكد مصر فى مفاوضات سد النهضة على عدم المساس

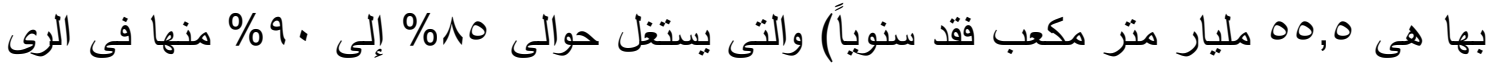
فى الزراعة وفى ضوء زيادة الطلب على المياه فى القطاعات الاخرى كمباه الثرب والصناعة

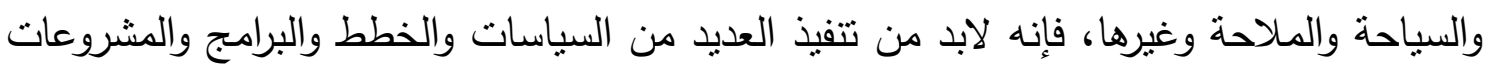


المشتركة بين وزارتى الزراعة واستصلاح الاراضى والموارد المائية والرى لترشيد استخدام مياه الرى فى الزراعة. ويمكن حصر عدد من تلاك السياسات والخطط والبرامج والمشروعات فى: - عدم السماح بل وتجريم استخدام نظام الرى السطحى أو الرى بالغمر في الاراضى الجديدة وقصر نظام الرى فى نلاك الاراضى على نظم الرى الحديثة كالرى بالرش والرى بالتتقيط.

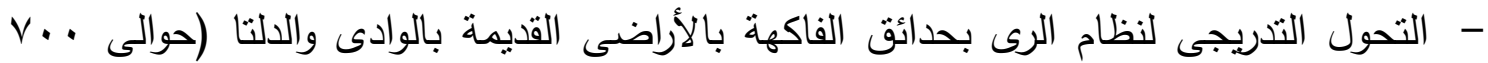
ألف فدان) من الرى السطحى أو الرى بالغمر إلى نظم الرى الحديثة.

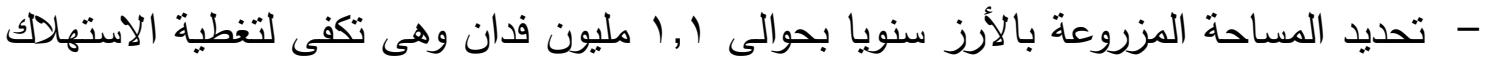

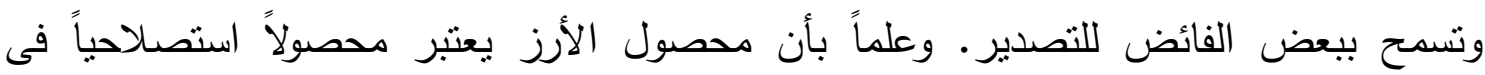
محافظات زراعة الأرز بشمال ووسط الدلتا ويساعد على غسيل التربة وعدم تملحها كما يعتبر حاجزاً لمياه البحر بتلك الدحافظات. - عدم زيادة المساحة المزروعة بالقصب عن المساحة المزروعة منه حاليا (10 ب إلى ... ب ألف فدان) وهى تكفى لتغطية حاجات مصانع قصب السكر بالوجه القبلى. - تطوير وتحسين نظام الرى السطحى أو الرى بالغمر بالأراضى القديمة بالوادى والدلتا من خلال

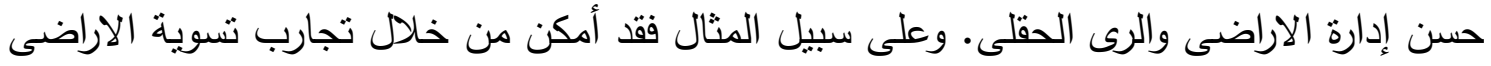

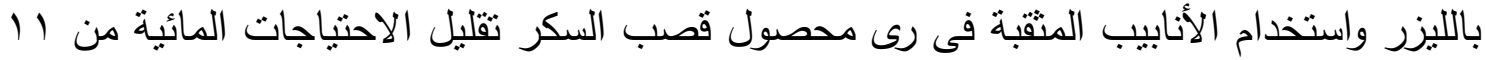
ألف متر مكعب إلى ^^ آلاف متر مكعب للفدان. كما أمكن من خلال المشروع المشترك بين وزارتى الزراعة واستصلاح الاراضى والموارد المائية والرى لتطوير الرى الحقلى والممول من منح وقروض تطبيق نظام الرى السطحى المطور وذلك بالنسبة لبعض الدحاصيل الحقلية الاخرى كالقمح والبنجر والقطن والارز عند بعض المزارعين فى بعض المحافظات كالبحيرة وكفر الثيخ

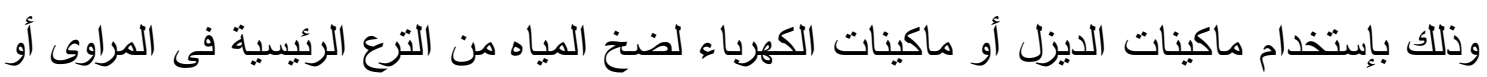


المساقى المبطنة أو فى مواسير حتى رأس الحقل مما يقلل أو يمنع الفقد فى المياه أثناء مرحلة

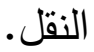
- التوسع فى استتباط واستخدام أصناف من المحاصيل قصيرة العمر وذات إحتياجات مائية أقل.

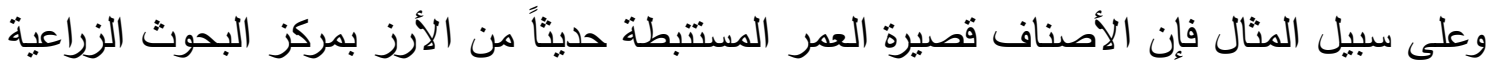

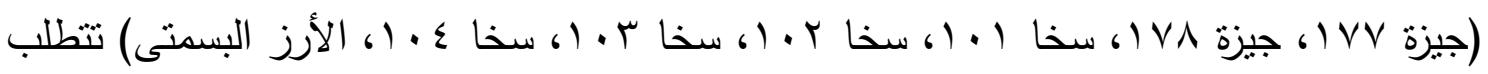

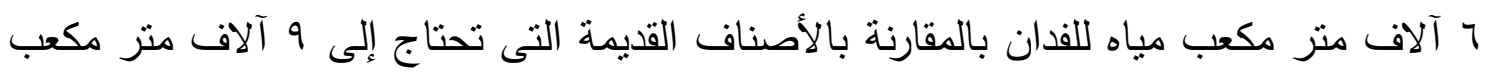
مياه للفدان. - النتوسع فى إعادة استخدام مياه الصرف الزراعى المعالج فى الرى. - التوسع فى نحلية المياه الجوفية لاستخدامها فى الرىى.

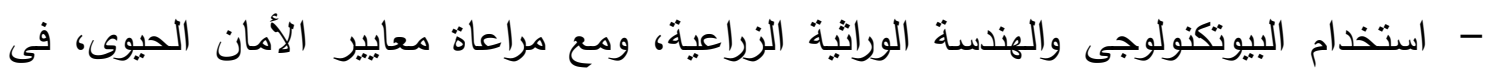
استتباط أصناف من المحاصيل مقاومة للظروف المعاكسة أو الاجهاد البيئى كالدرارة والجفاف الهاتف

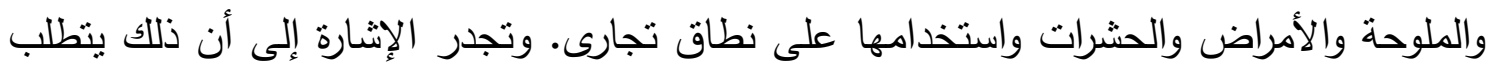

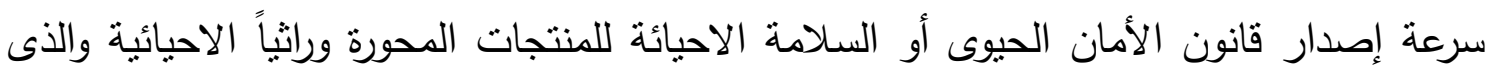

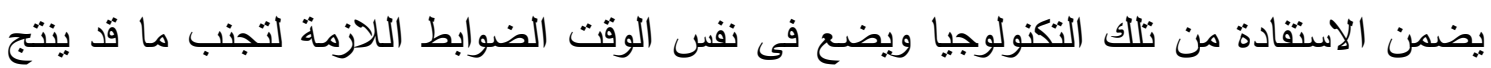
عنها من آثار جانبية على صحة الانسان والحيوان والبيئة. - التوسع فى تبطين وتغطية المراوى والمساقى والقنوات الصغيرة بالأراضى القديمة فى الوادى والدلتا.

$$
\text { - - تدعيم برامج الإرشاد الإروائى. }
$$
- الأخذ فى الاعتبار عند رسم التركيب المحصولى التأثيرى سنويا العائد الصافى للمحصول ليس التهاه فقط بالنسبة لوحدة الأرض (الفدان) وإنما أيضا بالنسبة لوحدة المياه (المتر المكعب). 
وجدير بالذكر أنه يمكن من خلال تتفيذ تلك السياسات والخطط والبرامج والمشروعات توفير حوالى ملى • 1 مليار متر مكعب مياه سنويا يمكن استخدامها فى استصلاح واستزراع أراضى جديدة. ويمكن للاولة توفير التمويل اللازم لتتفيذ سياسات وخطط وبرامج ومشروعات ترشيد استخدام مياه الرى فى لئ

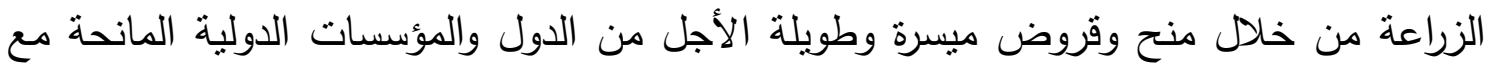
إمكانية تحمل الدولة لنصف التكلفة دعما للمزارعين وتقسيط النصف الباقى عليه وعلى فتزة طويلة وذللك منلما حدث مع مشروعات الصرف المغطى.

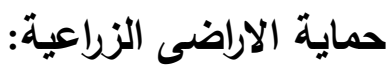
وجدير بالذكر أن استصلاح واستزراع أراضى جديدة لايعنى عدم الاهتمام بالأراضى القديمة

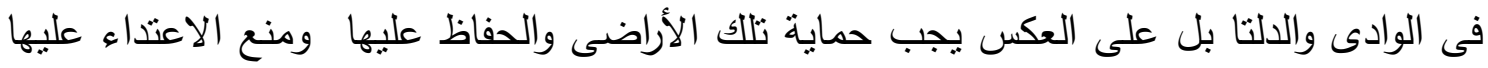
وصيانتها وتحسينها وتتميتها (تبلغ المساحة المنزرعة بمصر حاليا حوالى 9 مليون فدان منها

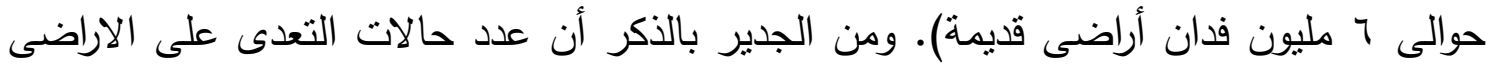

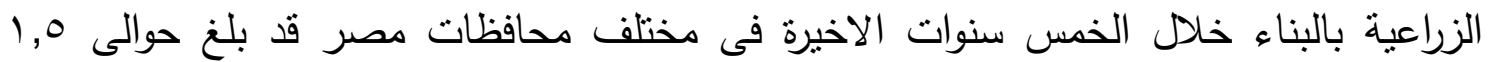

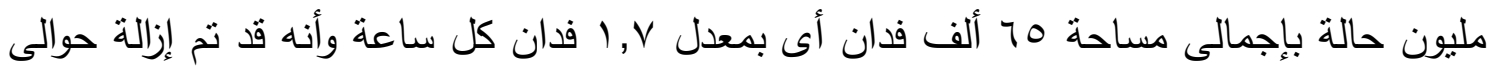
AV

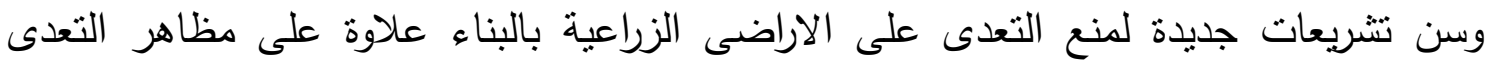
الاخرى كالتبوير والتجريف وتظليظ العقوبة على المخالفين. ومع العمل فى نفس الوقت على التى الاستفادة من الظهير الصحراوى بالمحافظات فى توفير فرص للإسكان ومواجهة مشكلة البناء على الصى الاراضى الزراعية. كما يمكن النظر فى التخطيط العمرانى للقرى. هذا وقد نص الدستور المصرى

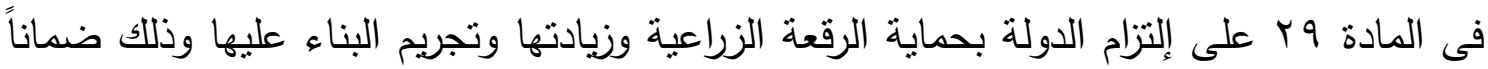

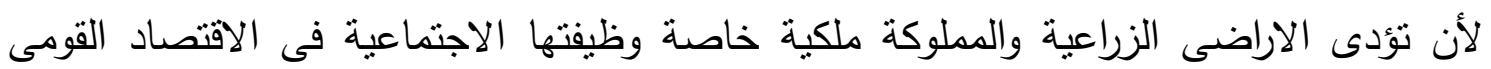

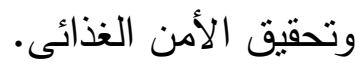


• استمرار برامج النتوسع الرأسى أى زيادة إنتاجية الوحدة من الارض والمياه والعمل ورأس المال

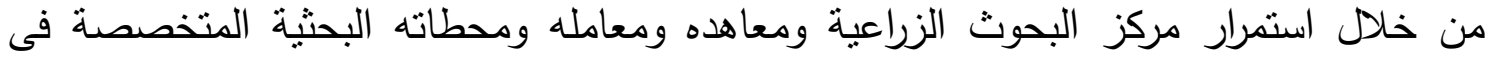

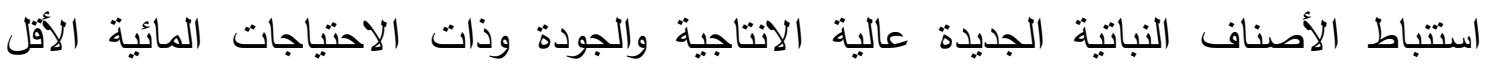

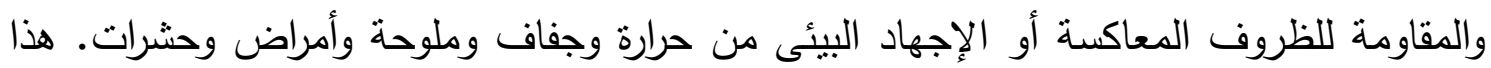

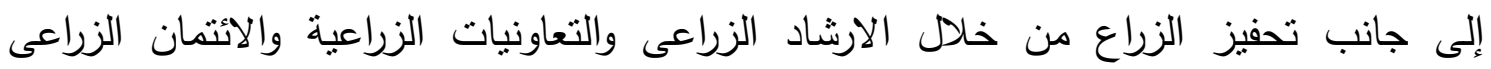

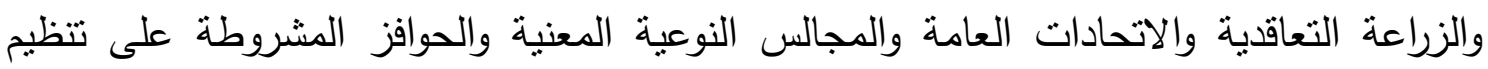

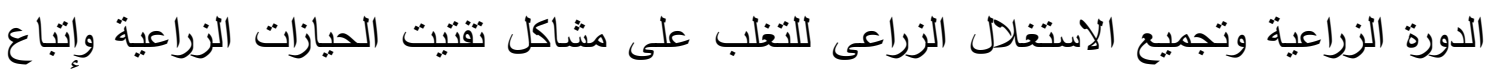

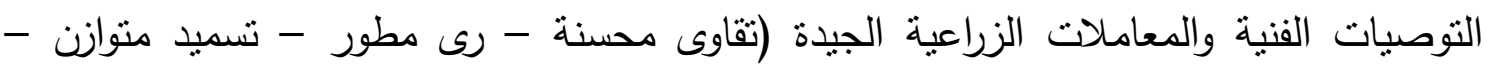

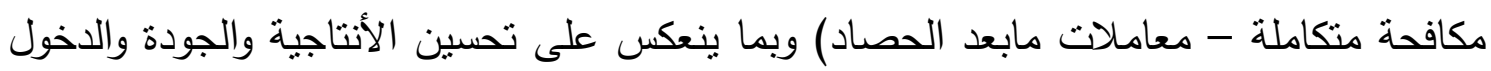

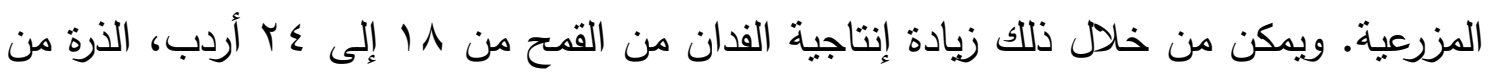

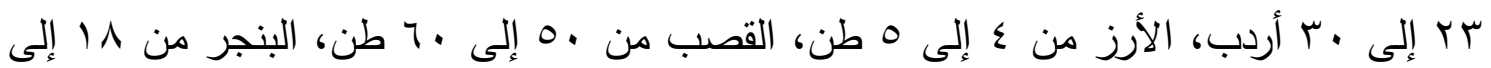

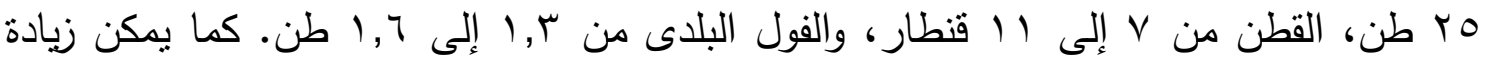

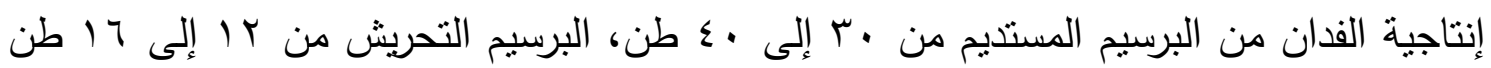

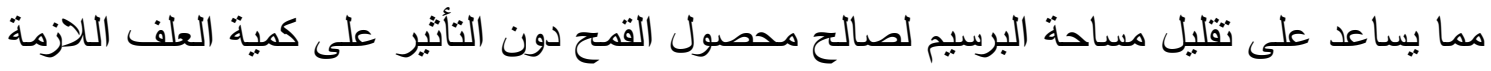

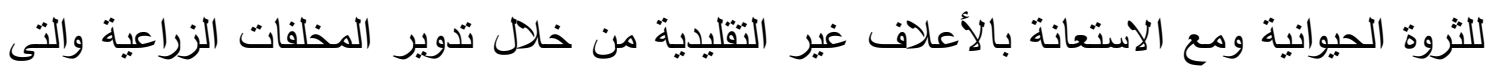

$$
\begin{aligned}
& \text { تصل إلى حوالى VY مليون طن سنويا. } \\
& \text { توفير مستلزمات الانتاج النزاعى: }
\end{aligned}
$$

• توفير مستلزمات الانتاج الزراعى(التقاوى المحسنة والاسمدة والمبيدات والميكنة) للمزارعين

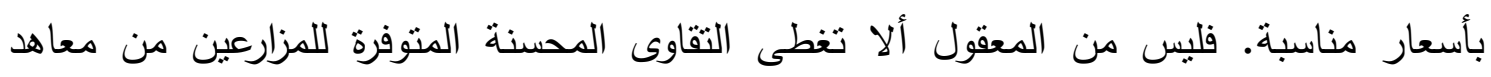

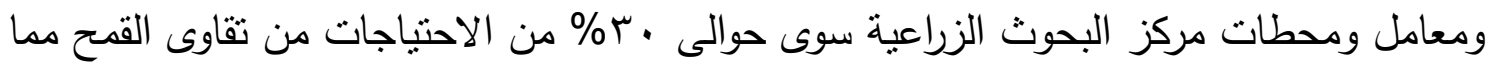


يضطر المزارعين إلى استخدام التقاوى المخزنة لديهر من سنوات سابقة وبما يؤدى إلى انخفاض الإنتاجية. كما يتطلب الأمر إنثاء مصانع للأسمدة الآزوتية فى الوجه القبلى. وإعادة تأهيل

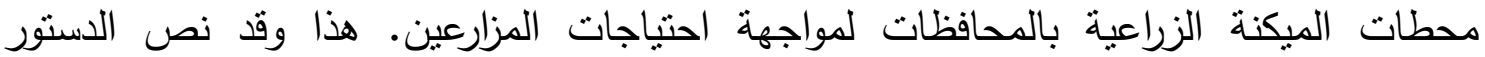
المصرى على توفير مستلزمات الإنتاج الزراعى النباتى والحيوانى. تحقيق التراكيب المحصولية المثلى التأثبرية:

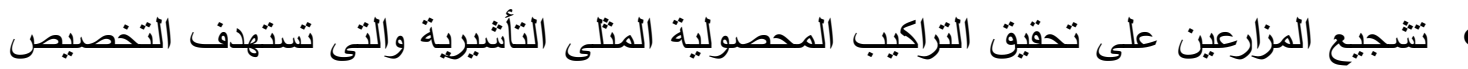
والاستخدام الأمتل للموارد الزراعية المتاحة وذلك من خلال تبنى سياسات نسويقية وسعرية وغير سعرية ملائمة. وتحديد أسعار ضمان إختبارية مجزية للمحاصيل الإستراتيجية تأخذ فى الاعتبار تكاليف الإنتاج والأسعار العالمية وإعلانها للمزارعين قبل موسم الزراعة بوقت كاف والتوسع فى التى الزراعة التعاقدية بين المزارعين وجمعياتهم التعاونية من جهة والتجار والمسوقين والمصنعين والمصدرين من جهة ثانية. هذا وقد نص الدستور المصرى على شراء المحاصيل الزراعية

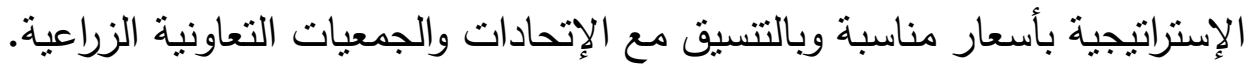
تحسين نسب الاكتفاء الذاتى من المحاصيل الغذائية الإستراتيجية:

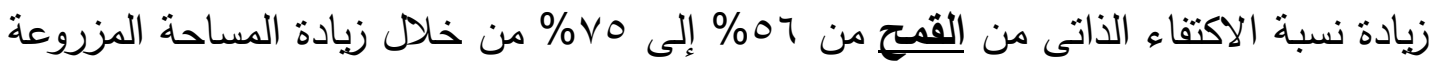

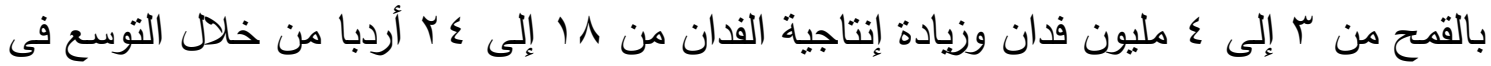
توفير التقاوى المحسنة بأسعار مناسبة وتفعيل برامج الارشاد الزراعى لدعوة المزارعين إلى إتباع

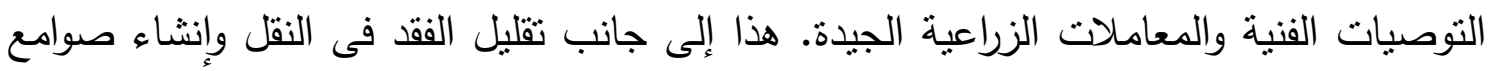
للتخزين وتحسين صناعة الخبز ومنع تسرب دقيق الخبز وتقليل الاستهلاك غير الآدمى وترشيد

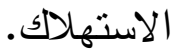

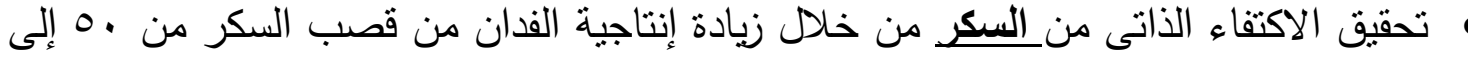

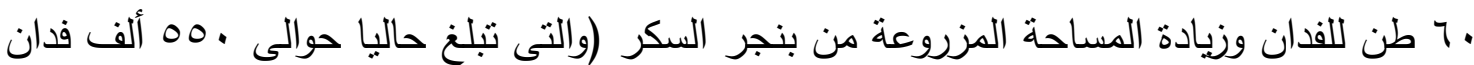


سنوياً) وزيادة إنتاجية الفدان منه من ^1 إلى 1 ب طنا وإنثاء مصانع سكر بنجر جديدة مع فرض رسوم على الواردات من السكر فى حالة إنخفاض الاسعار العالمية وتحديد حصص للاستيراد بما يغطى الفجوة بين الانتاج والاستهلاك فقط وذلك منعاً للإغراق وحماية لصناعة السكر الوطنية.

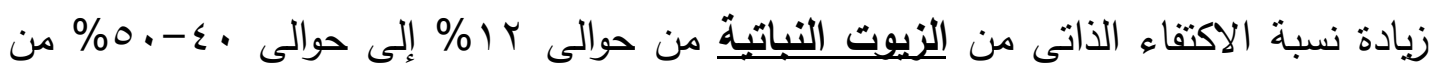

خلال زيادة مساحة وإنتاجية القطن والمحاصيل الزيتية الأخرى (فول الصويا - عباد الثمس الفول السودانى- السمسم- الكانولا- الزيتون) وتشجيع إقامة مصانع الزبوت والتعاقد مع المزارعين.

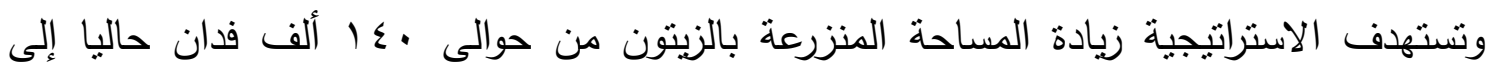
حوالى . وب ألف فدان مع توفير المعاصر اللزمة لذلك لصغار المزارعين وشباب الخريجين. وتعتبر سيناء ومطروح من المناطق الواعدة لذلك. كما أنه من المعروف أن الزبيتون تصلح زراعته لوفه فى الاراضى الهامشية كما أنه يتحمل ملوحة المياه والتربة.

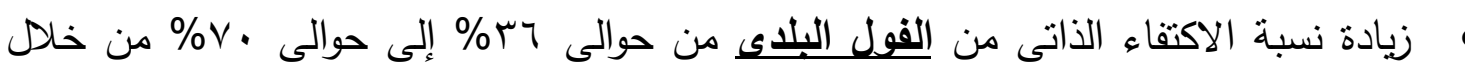

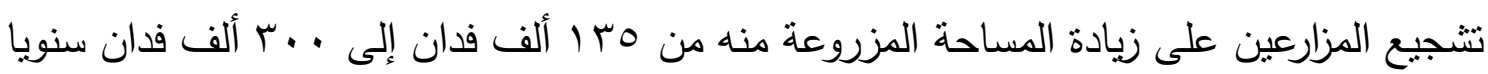

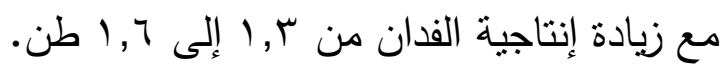
زبادة نصيب الفرد من البروتين الحيوانى من مصادره المختلفة من حوالى 19 جرام فى اليوم حاليا إلى حوالى گr جرام يوميا خلال السنوات الخمس القادمة وذللك من خلال: - تطوير قطيع الماثية والاغنام والماعز المصرية والتحسين الوراثى لسلالاتها لرفع قدرتها الإنتاجية دن اللحوم والألبان (يصل حجم إنتاج اللحوم الحمراء حاليا إلى حوالى . . ألف طن سنوبا فى حين أن حجم الاستهلاك يصل إلى حوالى مليون طن سنوبا أى بنسبة اكتفاء ذاتى حوالى • • \% . وبالنسبة للألبان الطازجة يصل حجم الإنتاج حاليا إلى حوالى 7 مليون طن سنويا ويتم استيراد حوالى •^ ألف طن لبن بودرة تعادل حوالى نصف مليون طن لبن سنويا) والتوسع فى الإج مشروع البتلو بدءاً بتربية وتسمين مليون رأس ماشية وإعطاء العناية الواجبة من الرعاية البيطرية 
لحماية قطعان المانية من الامراض المتوطنة والوافدة كالجلد العقدى والحمى القلاعية وحمى

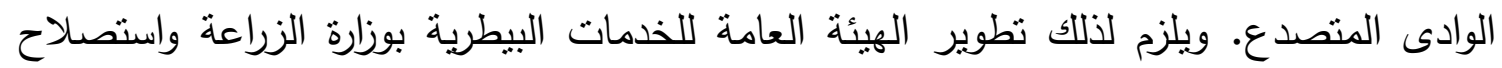
الاراضى من خلال برنامج للتوأمة مع نظيراتها فى بعض الدول الاوروبية من خلال المعونة الفنية التى يتيحها اتفاق المشاركة المصرية الأوروبية.

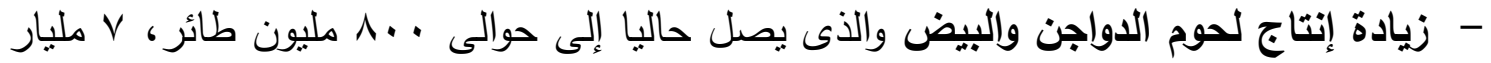

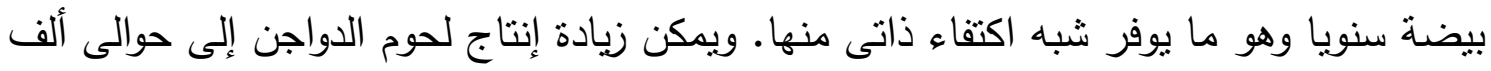

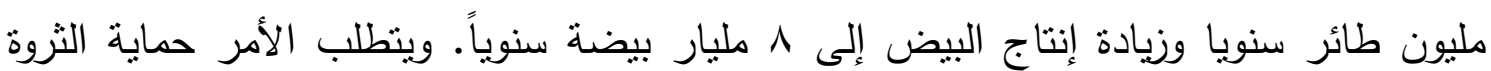
الداجنة من الأمراض المنوطنة والوافدة وخاصة إنفلونزا الطيور ومراعاة معايير الأمان الحيوى الفيات وتتجيع إنثاء مجازر وثلاجات الدواجن ومنع تداول الطيور الحية والإبقاء على فرض رسوم على الطى الواردات من الدواجن وحظر استيراد أجزاء الدواجن وذللك لحماية صناعة الدواجن الوطنية وحث الإتحاد العام لمنتجى الدواجن على التعاقد مع المزارعين لزراعة الذرة اللازمة كعلف للاواجن

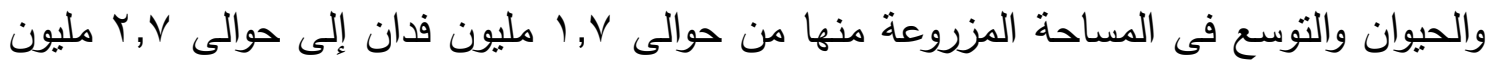

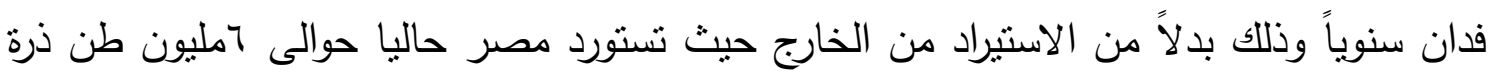

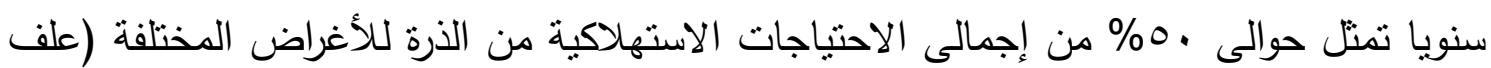
دواجن، علف حيوان، نشا وجلوكوز ... إلخ). - تنمية الثروة السمكية سواءاً فى نهر النيل أو البحرين المنوسط والأحمر مع إعادة إنثاء

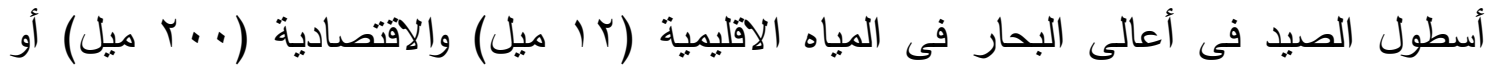

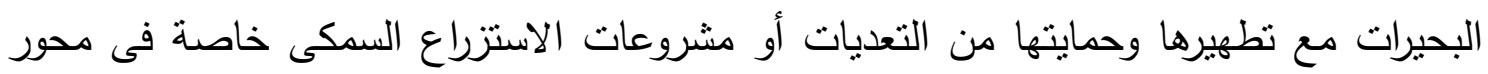
قناة السويس ومحافظة كفر الثيخ مع السماح باستخدام المياه العذبة فى المزارع السمكية والسماح بحق الاتتفاع لفترات طويلة فى مجال تتمية الثروة السمكية وخاصة للمستثمرين الذين يستخدمون تكنولوجيا حديثة وتفعيل دور الهيئة العامة لتتمية الثروة السكية فى الإرشاد والمعونة الفنية والرقابة 


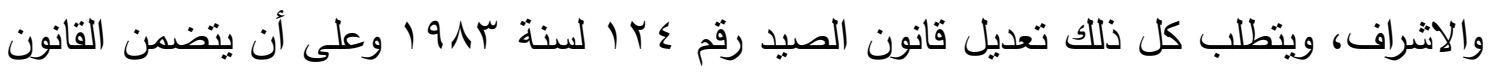
أيضا شروط الصيد وتثنديد العقوبات على المخالفات.

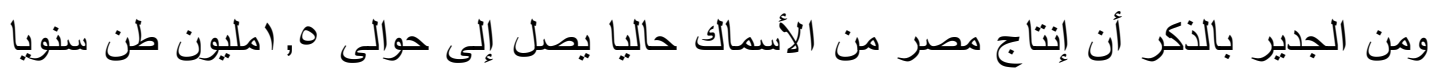

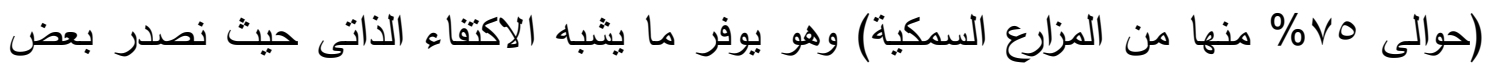

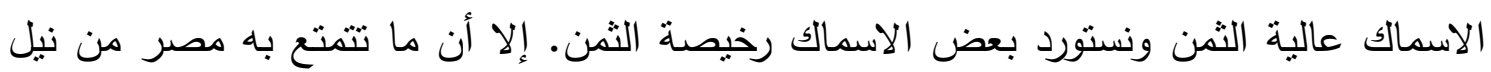

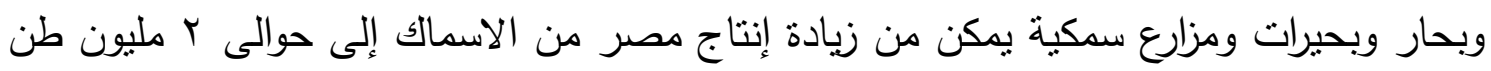

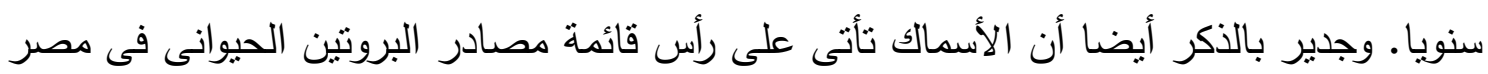
من حيث المزايا النسبية والتتافسية ويليها لحوم الدواجن ثم البيض ثم الألبان فاللحوم الحمراء نظراً لأن مصر ليست دولة مراعى طبيعية.

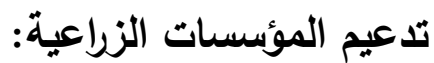
تدعيم المؤسسات الزراعية (وبما ينطلبه ذلك من تعديلات تتريعية فى قانون الزراعة رقم

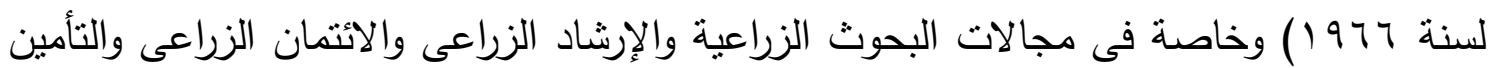

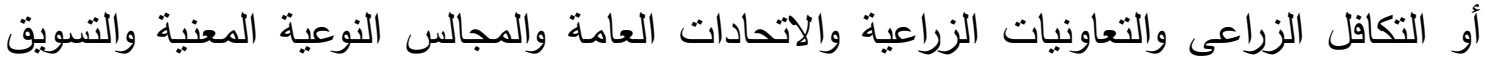
الزراعى والحجر الزراعى والحجر البيطرى والصيد والتعليم والتدريب الزراعى لكى تقوم بدور أكبر التراعيه فى تحقيق التنمية الزراعية المتواصلة أو المستدامة. وفى هذا الإطار فقد صدر قانون بتعديل

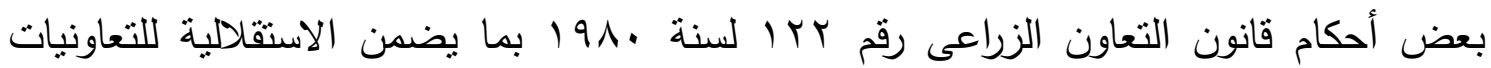

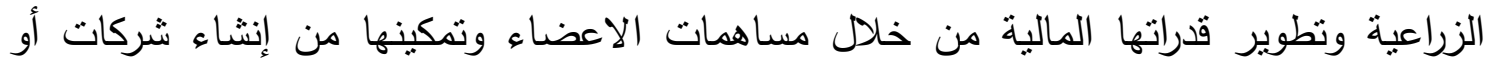

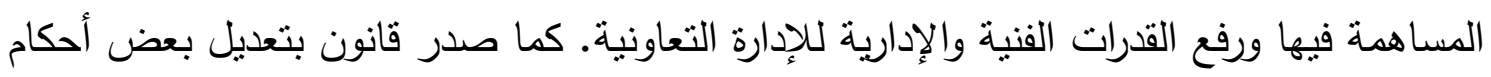
القانون رقم VII ل لسنة 19 I فى شأن البنك الرئيسى للتتمية والائتمان الزراعى بما يضمن إعادة

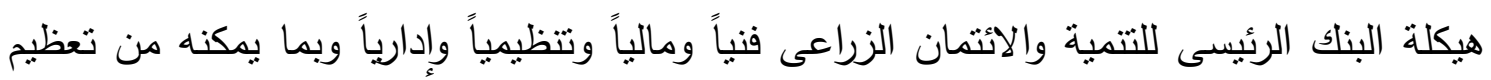


دوره المصرفى كبنك متخصص فى خدمة التتمية الزراعية والريفية وفصل النشاط التجارى عن

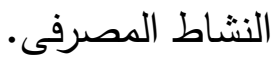
كما أن الدعم المؤسسى يتطلب إنشاء مجلس قومى للأكن الغذائى (فى إطار مجلس قومى

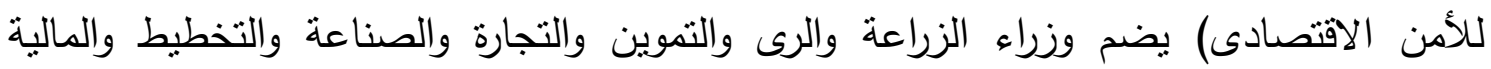
وممنلين للفلاحين.

\section{التوسع فى التصنيع الزراعى والغذائى:}

•الاهتمام بيرامج التصنيع الزراعى والغذائى والذى يشجع التوسع فى الزراعة التعاقدية (وما تتضمنه من الاتفاق على أسعار للمحاصيل قبل الزراعة والمساعدة فى توفير مستلزمات الإنتاج والإرشاد الزراعى وكذلك المساعدة فى معاملات ما بعد الحصاد) ويوفر فرصاً للعمل ويولد الدخل ويخلق قيمة مضافة ويحسن الجودة ويقلل الفقد فى الحاصلات الزراعية ويحقق نواجد السلعة طوال العام واستقرار الأسعار وإحلال الواردات وزيادة الصادرات. وينطلب الأمر التوسع فى إنشاء

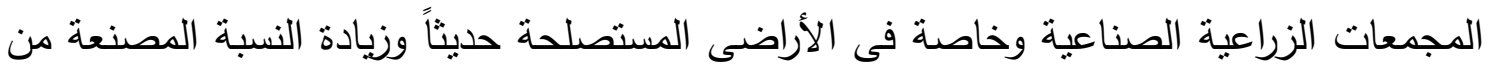

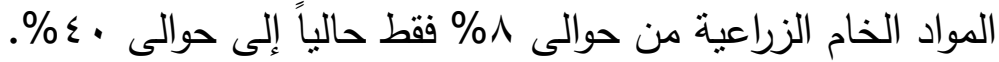

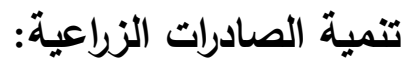
• العمل على زيادة الصادرات الزراعية وخاصة من المحاصيل التى تتمتع فيها مصر بميزة نسبية وتتافسية كالقطن والأرز والخضر والفاكهة والنباتات الطبية والعطرية وزهور القطف. ومن الجدير

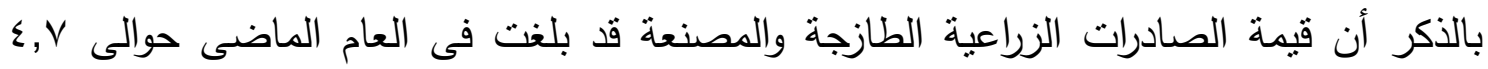

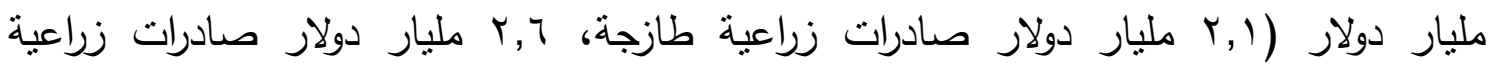

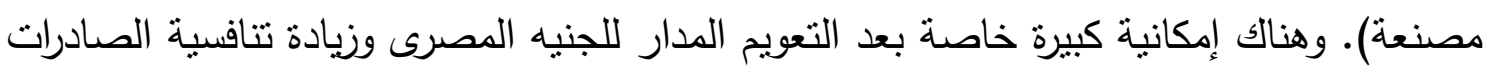
الزراعية المصرية زيادة هذه الصادرات سنويا بمعدل 0 \%\% إلى ·r\% وتخفيض العجز فى الميزان

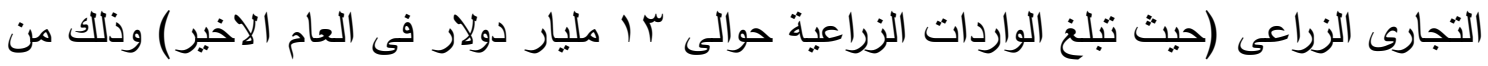


خلال النفاذ إلى الأسواق والذى تتيحه الاتفاقيات الدولية والاقليمية والعربية (منظمة التجارة العالمية،

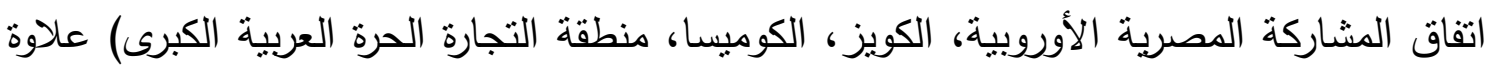
على البروتوكولات والاتفاقيات الثنائية بين مصر والدول الاخرى متل روسيا والصين. ومن الجدير بالذكر أن مصر لا تستقيد بدرجة كاملة من الحصص التصديرية الزراعبة

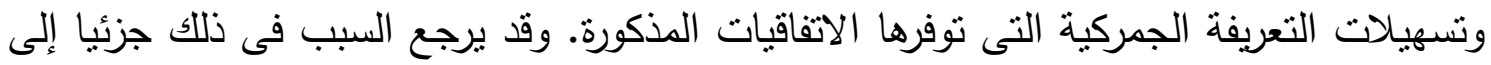
التثدد أكثر من اللازم أحيانا من جانب بعض الدول المستوردة من خلال ما بسمى بالمعوقات

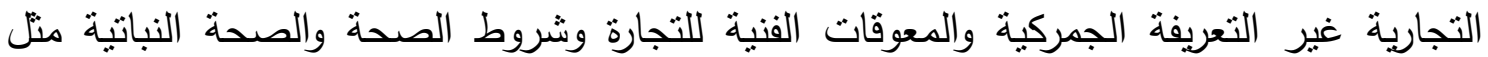

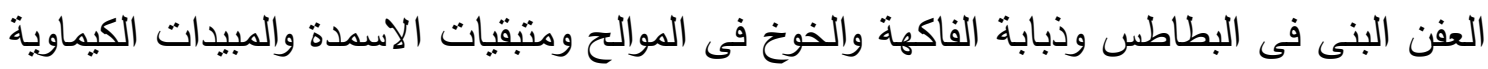
فى النباتات الطبية والعطرية. ولكن السبب الحقيقى فى عدم استيفاء مصر لحصصها التصديرية الزراعية يرجع إلى ضيق القاعدة التصديرية الزراعية. فعلى سبيل المثال نتتج مصر سنويا حوالى اب مليون طن من الت

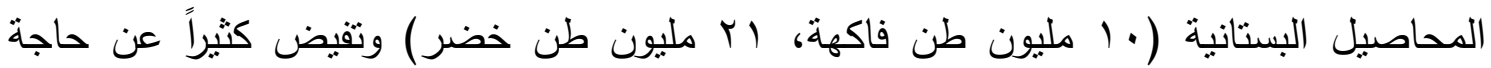
الاستهلاك ورغم ذلك لا يصدر منها سنويا إلا حوالى r,r مليون طن فقط (منها حوالى ... ألف لف

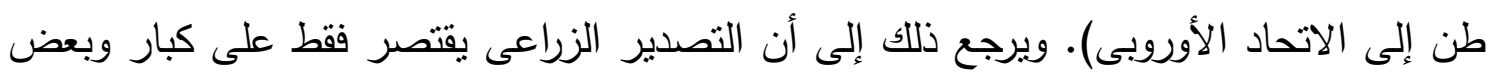

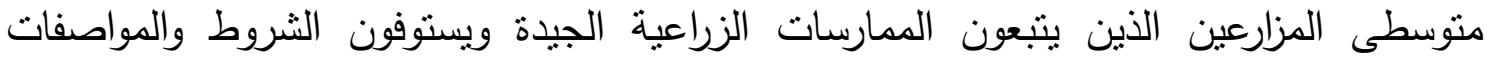
الأوروبية يوروب جاب والدولية جلوبال جاب للتصدير فى حين أن غالبية المزارعين فى مصر التمر

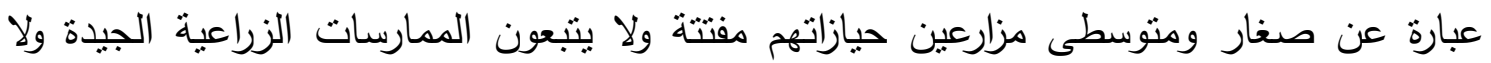

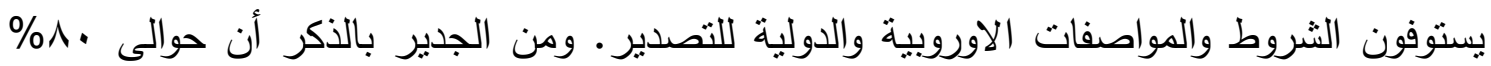
من الحيازات فى مصر أقل من ب فدان وحوالى •9\% من الحيازات أقل من ه أفدنة. ولربط هؤلاء المزارعين بالسوق المحلى والتصنيع والتصدير وزيادة الانتاجية والجودة وتحسين دخولهم فإن الامر يتطلب العمل على مساعدة هؤلاء المزارعين على تجميع الاستغلال الزراعى واتباع الممارسات 
الزراعية الجيدة طوال مراحل الإنتاج ومعاملات مابعد الحصاد واستيفاء الثروط والمواصفات

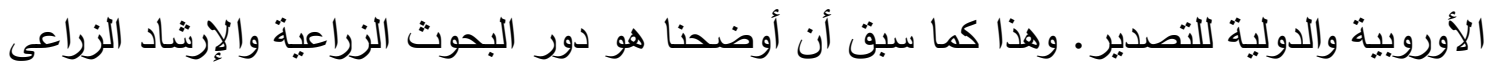
والتعاونيات الزراعية والايتمان الزراعى والزراعة التعاقدية والإتحادات العامة والدجالس النوعية المعنية والحوافز المشروطة. تكثيف الاستثمارات الزراعية:

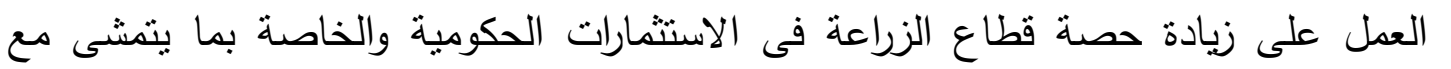
الطاقة الاستيعابية للقطاع وكذلك مع دوره فى الاقتصاد القومى حيث بلغ متوسط نصيب قطاع

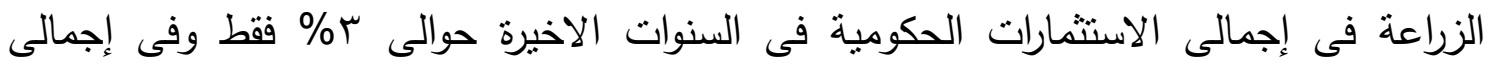

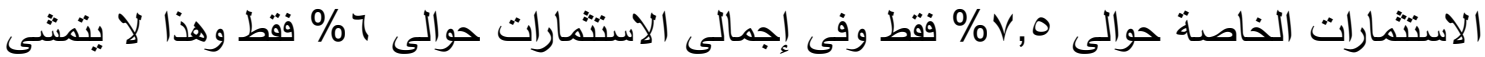

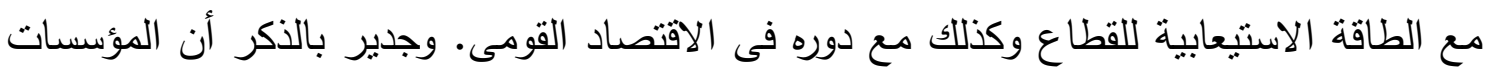
الدولية توصى بألا تقل نسبة الاستثمارات الزراعية فى الاستثمارات الحكومية فى الدول النامية عن النايه

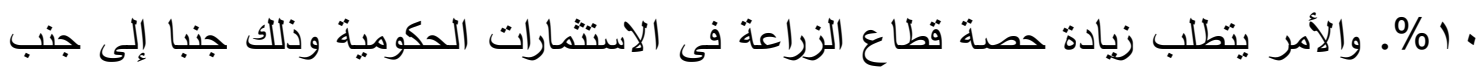

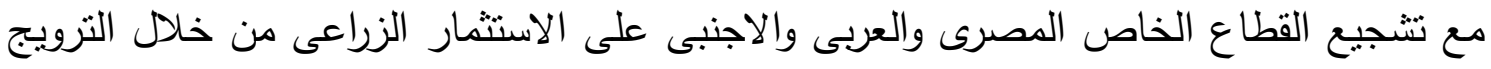
لفرص الاستثمار المتاحة فى المجالات المختلفة فى قطاع الزراعة وفى ضوء قرارات المجلس الإس

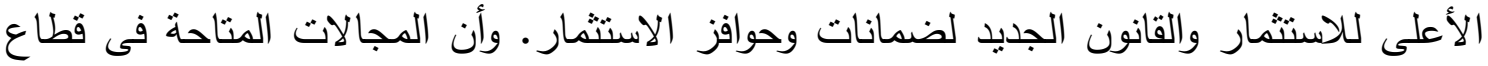
الزراعة واستصلاح الأراضى والتى يمكن أن تروج كفرص استثمارية تحت مظلة هذا القانون هى:

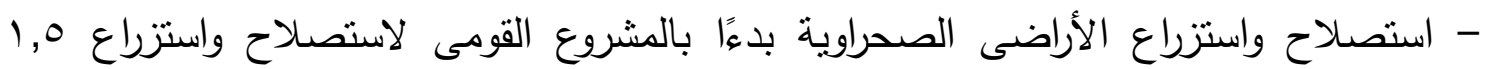

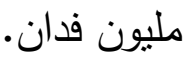
- الإنتاج النباتى وخاصة إنتاج محاصيل الزيوت وبنجر السكر والذرة والخضر والفاكهة والنباتات الطبية والعطرية وزهور القطف. 


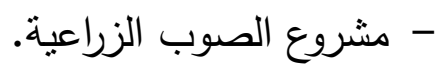

- مشروعات تدوير مياه الصرف وتحلية المياه.

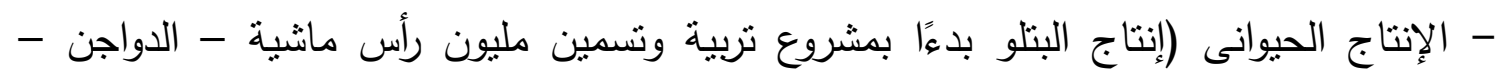
الأسماك سواءاً فى نهر النيل أو البحرين المتوسط والأحمر أو البحيرات أو المزارع السمكية خاصة لهنة مشروع الاستزراع السكى فى محور قناة السويس وفى محافظة كفر الثيخ).

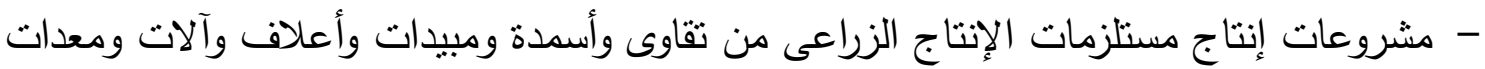
زراعية وأمصال ولقاحات بيطرية. - إنشاء مجازر وثلاجات للاواجن. - مشروعات التصنيع الزراعى والغذائى ومعاملات مابعد الحصاد للمحاصيل الزراعية (وخاصة الخضر والفاكهة والنباتات الطبية والعطرية والزيوت وبنجر السكر ). - إنتاج الوقود الحيوى (الإيثانول والبيوديزل) اعتماداً على المحاصيل الزراعية غير ولئر الغذائية

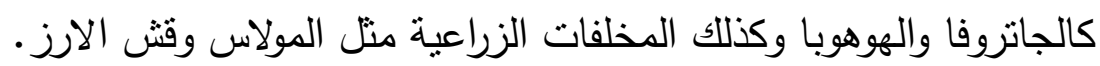
- مشروعات تدوير المخلفات الزراعية لإنتاج الأعلاف غير التقليدية والأسمدة العضوية. - البحوث الزراعية ونقل التكنولوجيا وخاصة فى مجالات البيوتكنولوجى والهندة الوراثية

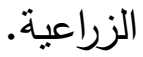
- مشروعات التسويق الزراعى والتجارة الخارجية للسلع الزراعية ومستلزمات الإنتاج الزراعى. دعم برامج التعاون الزراعى بين مصر والدول العربية والإفريقية:

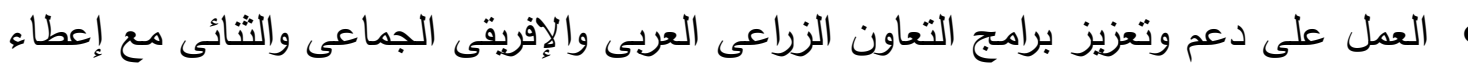
أهمية خاصة للتعاون الزراعى الإنتاجى والتجارى والمائى بين مصر ودول حوض الترائ النيل. 


\section{التوصيات}

في مجال إدارة مشروعات استصلاح واستزراع أراضي جديدة ( التوسع الأفقي ):

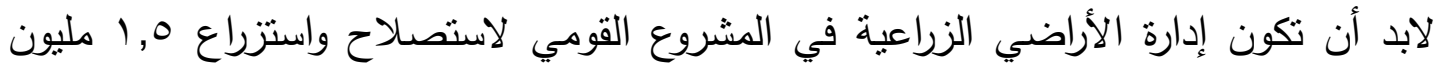

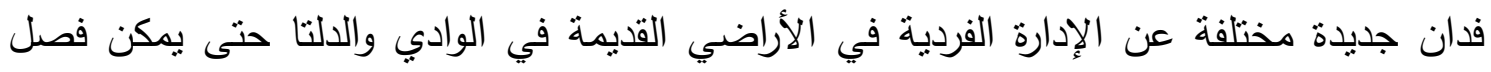
الملكية عن الإدارة وذلك من خلال شركات مساهمة أو جمعيات تعاونية أو شركات إدارة أعمال زراعية لتجنب مشاكل تفتيت الحيازات والاستفادة من وفورات السعة واستخدام التكنولوجيات الحديثة

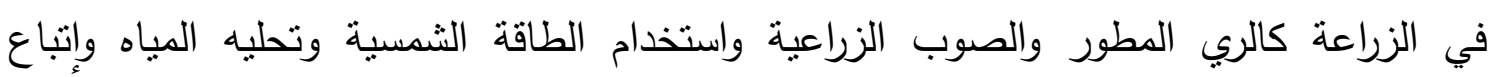

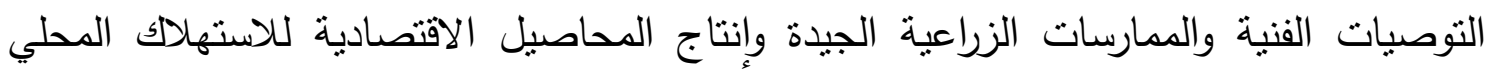
والتصدير وذات الاحتياجات المائية الأقل. ويرتبط بذللك كله التوسع في التصنيع الزراعي والغذائي

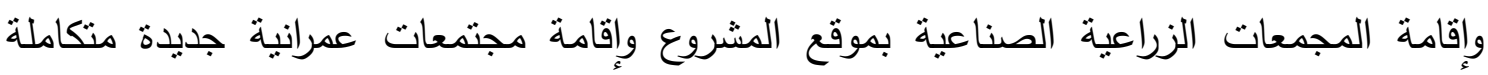
الجوانب من حيث الإتتاج والخدمات وذللك لزيادة المساحة المأهولة في مصر (والتي تبلغ حوالي التئي

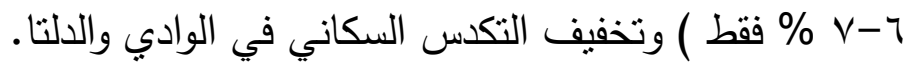
في مجال ترشيد استخدام مياه الري:

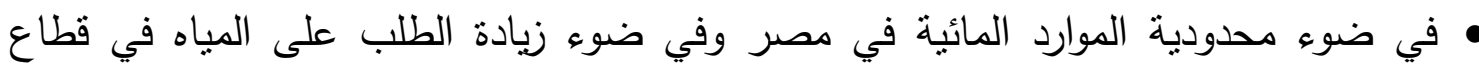

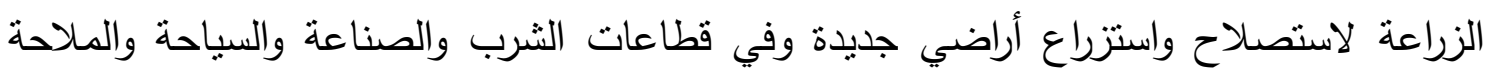

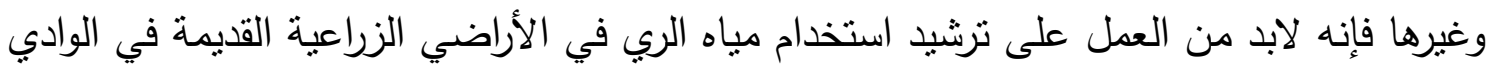

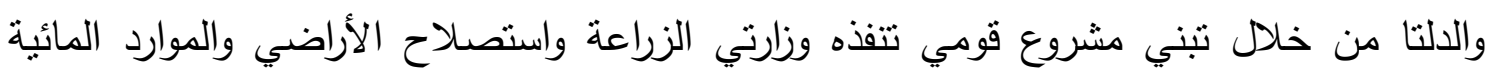

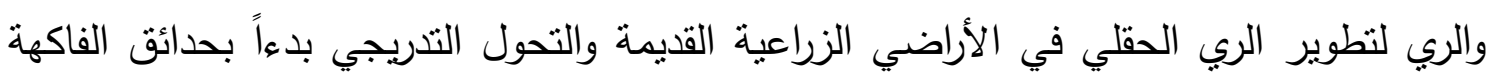

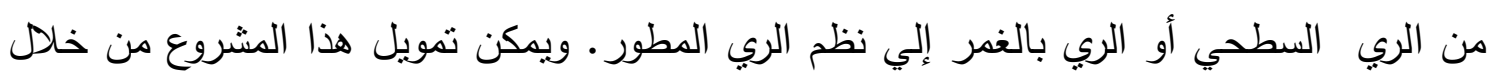

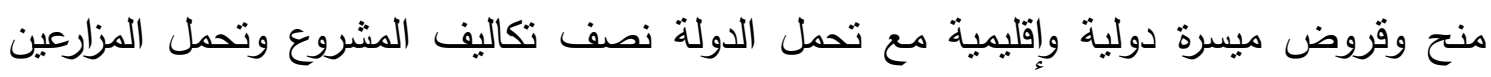


للنصف الآخر وخلال مدة طوبلة هب-.0 سنة وبفائدة بسيطة وذلك أسوة بما تم مع مشروع الصرف المغطي. عدم زيادة المساحات المزروعة بالمحاصيل عالية الاحتياجات المائية كالقصب والأرز عن

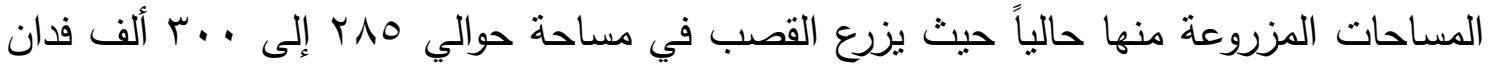

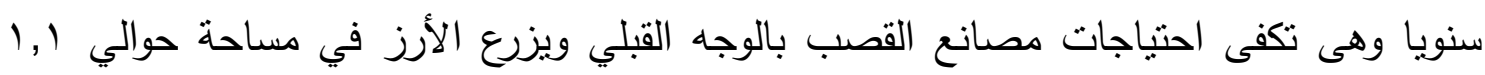
مليون فدان وهي تكفي احتياجات الاستهلاك المحلي مع كميات محدودة للتصدير . تدعيم موارد مركز البحوث الزراعية لكي يتمكن من الاستمرار في استتباط أصناف جديدة من المحاصيل الزراعية عالية الإنتاجية والجودة وذات احتياجات مائية اقل ومقاومة للظروف المعاكسة أو الإجهاد البيئي منل التغيرات المناخية العالمية والحرارة والجفاف والملوحة والأمراض والحشرات. • ضرورة الإسراع في إصدار قانون الأمان الحيوي أو السلامة الإحيائية للمنتجات المحورة وراثياً بما يمكن الاستفادة من تكنولوجيا الهندسة الوراثية في استتباط أصناف جديدة من المحاصيل الزراعية عالية الإنتاجية والجودة ومقاومة للظروف المعاكسة واستخدامها على نطاق تجاري ويضدن في نفس الوقت وضع الضوابط اللازمة لتجنب ما قد ينتج عنها من أثار جانبية على صحة الإنسان والحيوان والبيئة. •التوسع في إعادة استخدام مياه الصرف الزراعي المعالج في الري والتوسع في تحليه المياه.

\section{في مجال حماية الأراضي الزراعية:}

في ضوء زيادة التعدي على الأراضي الزراعية ( بمعدل حوالي V, أ فدان كل ساعة ) فإن الأمر قد يتطلب إعادة أمر الحاكم العسكري وسن نشريعات جديدة لمنع التعدي على الأراضي الزراعية بالبناء علاوة على مظاهر التعدي الأخرى كالتبوير والتجريف وتغليظ العقوبة على المخالفين. ومع العمل في نفس الوقت على الاستفادة من الظهير الصحراوي بالمحافظات في توفير فرص للإسكان ومواجهة مشكلة البناء على الأراضي الزراعية. كما يمكن النظر في التخطيط 
العمراني للقرى. وجدير بالذكر أن الدستور المصري قد نص على حماية الرقعة الزراعية وزيادتها وتجريم البناء عليها.

\section{في مجال زيادة الإنتاجية (التوسع الرأسي):}

نظراً لوجود فوارق كبيرة بين الإنتاجية الفدانية من مختلف المحاصيل الزراعية في محطات البحوث والتجارب الزراعية والحقول الإرشادية من جهة وعند المزارعين من جهة آخري فان الأمر يتطلب تدعيم وتقوية جهاز الإرشاد الزراعي بالخريجين الجدد وبالإمكانيات المادية حتى يمكن لهذا الجهاز نقل نتائج البحوث والتكنولوجيا الحديثة إلي المزارعين وتدريبهم عليها وإقناعهم بها هذا إلي جانب تحفيز الزراع من خلال الإرشاد الزراعي والتعاونيات الزراعية والزراعة التعاقدية والحوافز المشروطة على تتظيم الدورة الزراعية وتجميع الاستغلال الزراعي وبما ينعكس على تحسين الإنتاجية والجودة والدخول المزرعية. • ضرورة توفير مستلزمات الإنتاج الزراعي (التقاوي المحسنة والأسمدة والمبيدات والميكنة). ومن الجدير بالذكر أن تقاوي القمح المحسنة لا تغطي سوى حوالي • ب\% من الاحتياجات مما يضطر المزارعين إلى استخدام التقاوي المخزنة لديهم من سنوات سابقة وبما يؤدى إلى انخفاض الإنتاجية. كما يتطلب الأمر إنشاء مصانع للأسمدة الآزوتية في الوجه القبلي وإعادة تأهيل محطات الميكنة الزراعية بالمحافظات. هذا وقد نص الدستور المصري على توفير مستلزمات الإنتاج الزراعي النباتي والحيواني. تشجيع المزارعين على تحقيق التراكيب المحصولية المثلى التاشيرية وذلك من خلال تبنى سياسات تسويقية وسعريه وغير سعريه ملائمة وتحديد أسعار ضمان اختيارية مجزية للمزارعين للمحاصيل الزراعية الإستراتيجية تأخذ في الاعتبار تكاليف الإنتاج والأسعار العالمية وإعلانها للمزارعين قبل موسم الزراعة والتوسع في الزراعة التعاقدية. هذا وقد نص الدستور المصري على 
شراء المحاصيل الإستراتيجية بأسعار مناسبة وبالتتسيق مع الاتحادات والجمعيات التعاونية

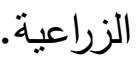

\section{في مجال تحسين نسب الاكتفاء الأتي من الغذاء:}

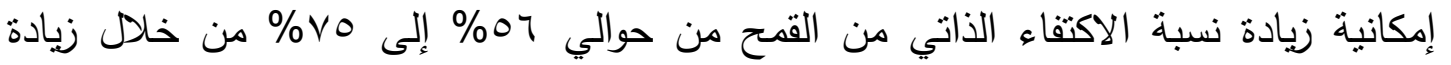

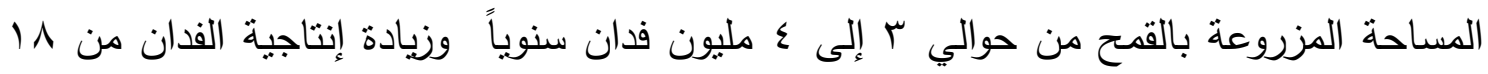

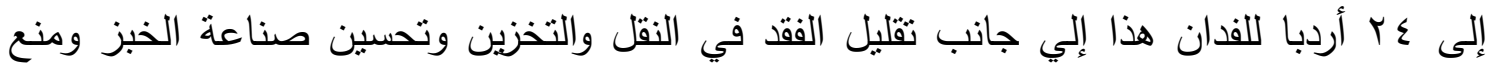
تسرب دقيق الخبز وتقليل الاستهلاك غير الآدمي وترشيد الاستهلاك.

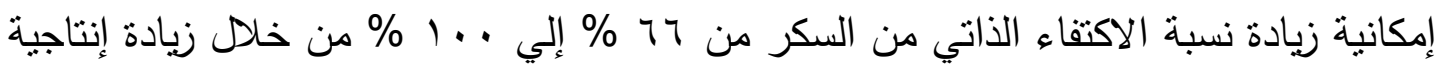

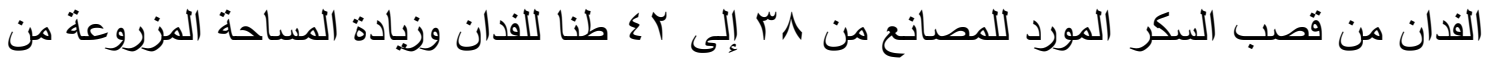
محصول البنجر والتي تبلغ حاليا حوالي نصف مليون فدان وزيادة إنتاجية الفدان من البنجر من

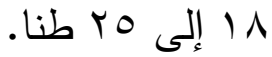

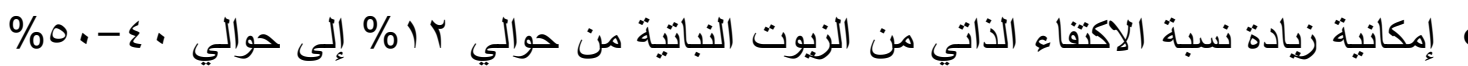

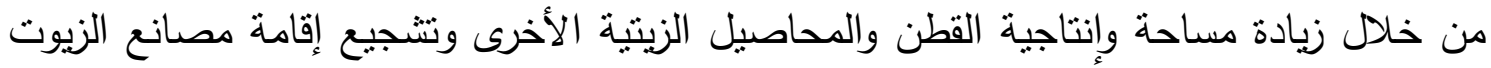

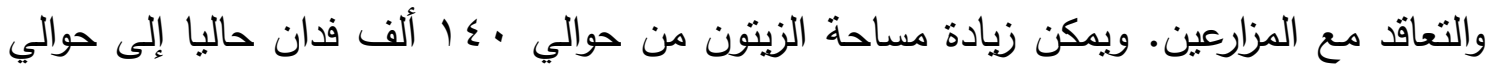

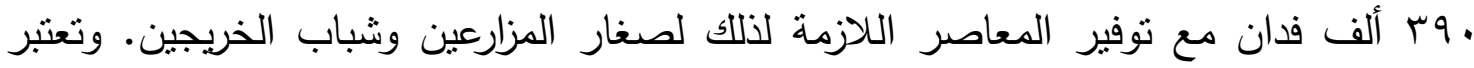
سيناء ومطروح من المناطق الواعدة لذلك كما أنه من المعروف أن الزينون تصلح زراعته في الأراضي الهامشية كما أنه يتحمل ملوحة المياه والتربة.

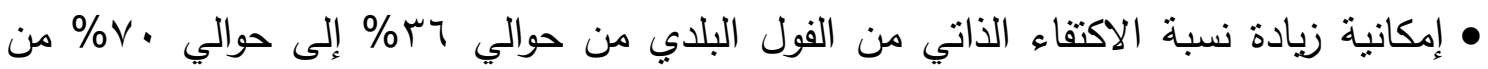

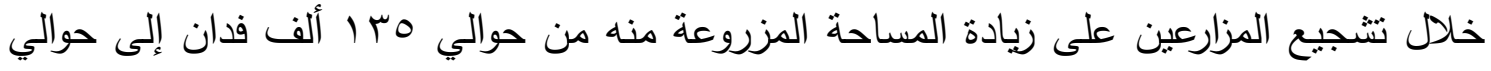

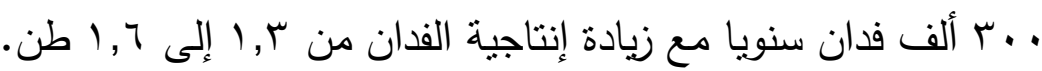


م إمكانية زيادة نصيب الفرد من البروتين الحيواني من مصادره المختلفة(الأسماك - لحوم الدواجن

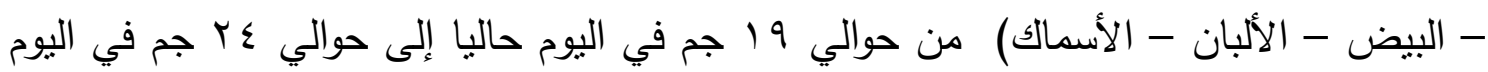

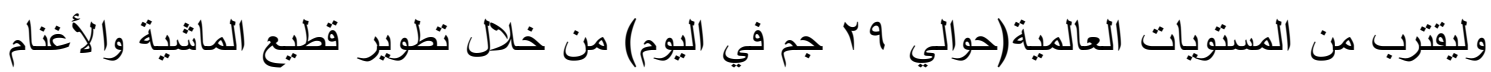

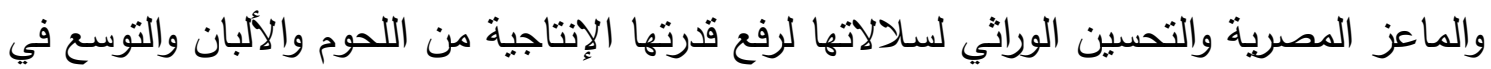

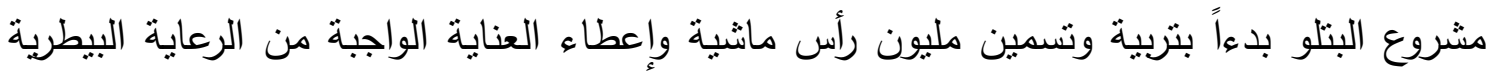

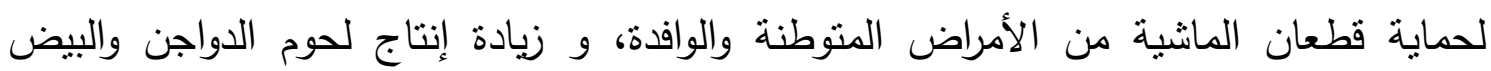

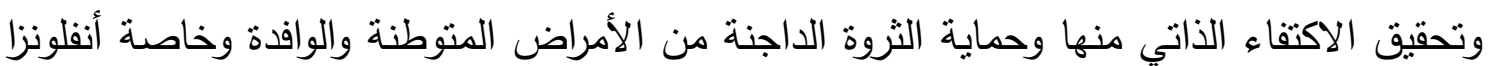

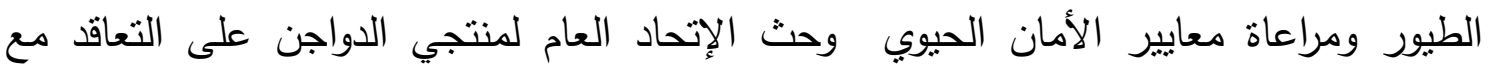

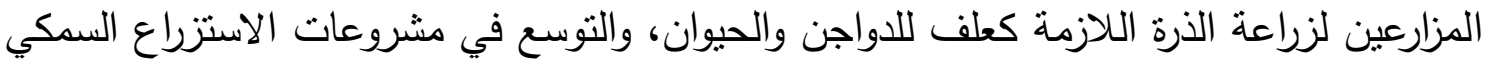

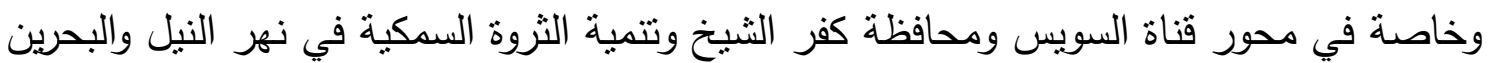

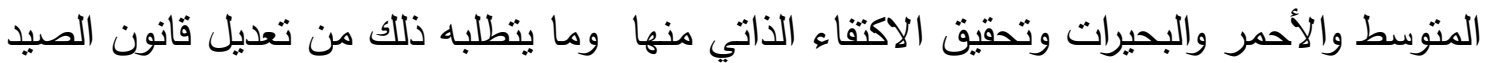

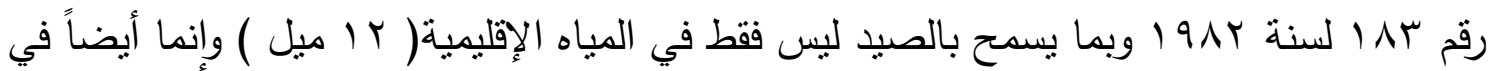

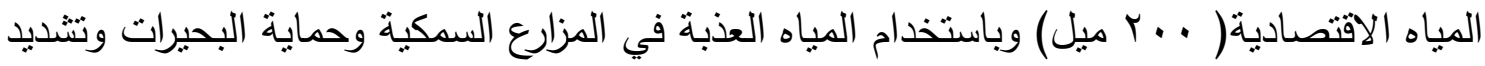
العقوبات على الصبد المخالف والسماح بحق انتفاع لفترات طويلة في مجال تتمية الثروة السمكية وخاصة للمستثمرين الذين يستخدمون تكنولوجيا حديثة.

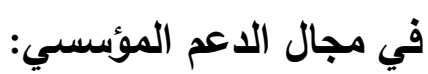

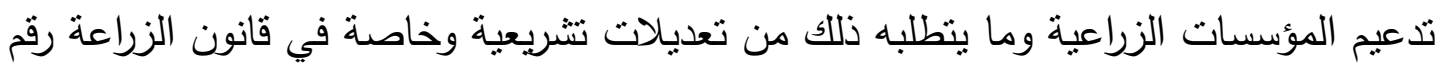
ror

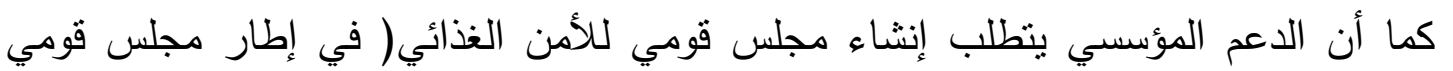
للأكن الاقتصادي) يضم وزراء الزراعة والري والتموين والتجارة والصناعة والتخطيط والمالية الطانية

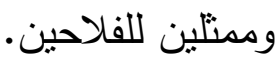




\section{في مجال التصنيع الزراعي والنذائي:}

التوسع في التصنيع الزراعي والغذائي وإنشاء المجمعات الزراعية الصناعية وخاصة في المشروعات القومية لاستصلاح واستزراع أراضي جديدة وزيادة النسبة المصنعة من المواد الخام

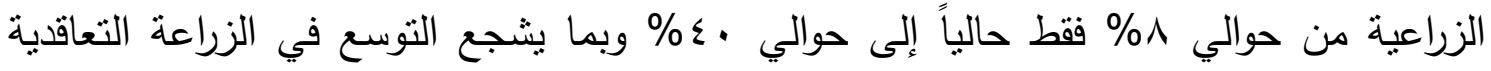
ويوفر فرصاً للعمل ويولد الدخل ويحقق قيمة مضافة ويحسن الجودة ويقلل الفقد في الحاصلات

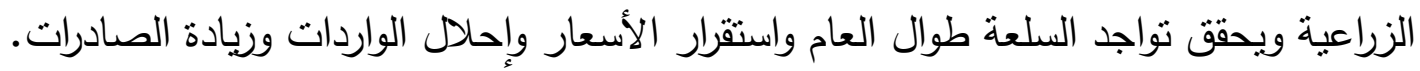

في مجال الصادرات الزراعية: • إمكانية زيادة الصادرات الزراعية الطازجة والمصنعة وخاصة من المحاصيل التي تتمتع فيها مصر بميزة نسبية وتتافسية كالقطن والأرز والخضر والفاكهة والنباتات الطبية والعطرية وزهور

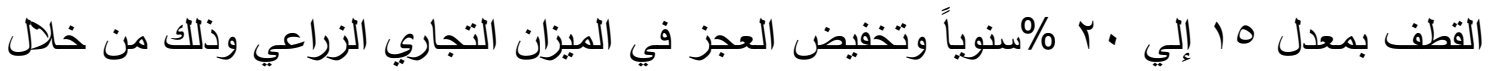
النفاذ إلى الأسواق والذي تتيحه الاتفاقيات الدولية والإقليمية والعربية والبروتوكولات والاتفاقيات

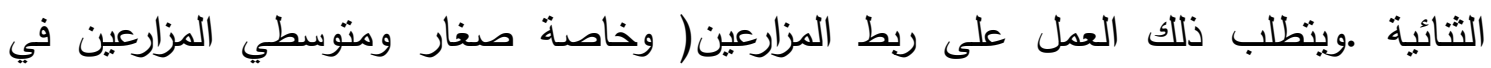
الأراضي القديمة بالوادي والدلتا والذين يمنلون الغالبية العظمي من المزارعين) بالسوق المحلي واليطي

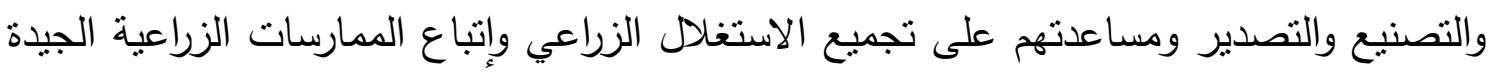

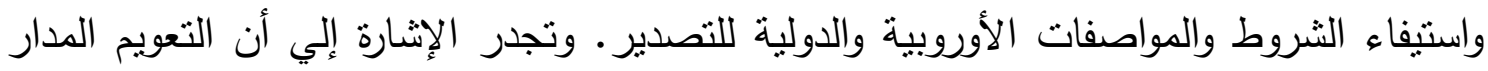
للجنيه المصري يحسن من تتافسية الصادرات الزراعية المصرية. في مجال الاستثمارات الزراعية:

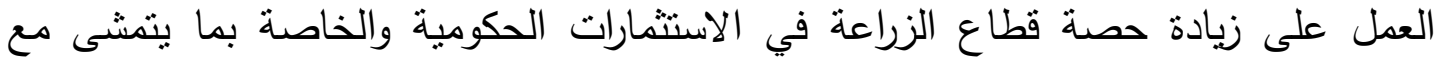
الطاقة الاستيعابية للقطاع ودوره في الاقتصاد القومي حيث أن منوسط نصيب قطاع التهاع الزراعة في

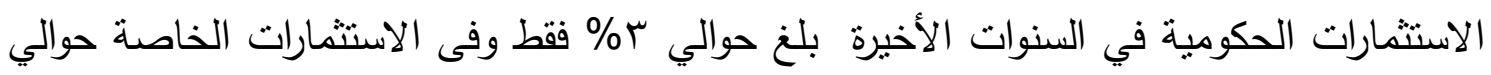

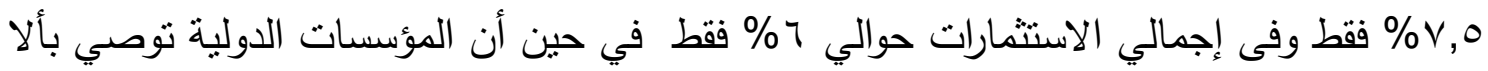


تقل نسبة الاستثمارات الزراعية في الاستثمارات الحكومية في الدول النامية عن ـ1 \% الأمر الذي

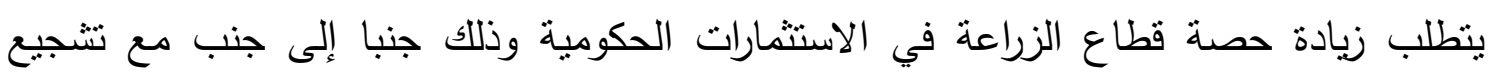

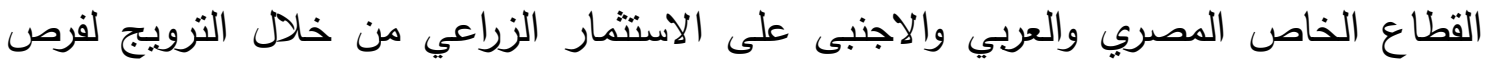
الاستثمار المتاحة في مجالات الإتتاج الزراعي بثقيه النباتي والحيواني الأفقي والراسي، إنتاج مستلزمات الإنتاج الزراعي، التصنيع الزراعي، البحوث الزراعية والتسويق الزراعي والتجارة

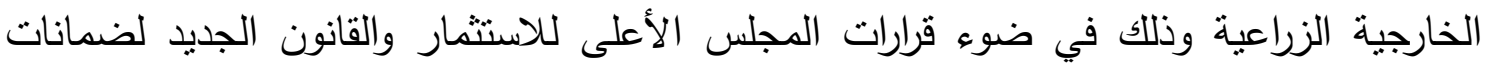

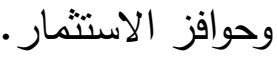

\section{في مجال التعاون الزراعي العربي والإفريقي:}

العمل على دعم وتعزيز برامج التعاون الزراعي العربي والإفريقي الجماعي والثنائي مع إعطاء أهية خاصة للتعاون الزراعي الإنتاجي والتجاري والمائي بين مصر ودول حوض النيل النيل. 